\title{
Aging and CMV discordance are associated with increased immune diversity between monozygotic twins
}

Zheng Yan ${ }^{1}$, Holden T. Maecker ${ }^{2}$, Petter Brodin ${ }^{3}$, Unni C. Nygaard ${ }^{1,4}$, Shu Chen Lyu ${ }^{1}$, Mark M. Davis², Kari C. Nadeau ${ }^{1}$ and Sandra Andorf ${ }^{1,5,6^{*}}$ (i)

\begin{abstract}
Background: Broadly, much of variance in immune system phenotype has been linked to the influence of nonheritable factors rather than genetics. In particular, two non-heritable factors: aging and human cytolomegavirus (CMV) infection, have been known to account for significant inter-individual immune variance. However, many specific relationships between them and immune composition remain unclear, especially between individuals over narrower age ranges. Further exploration of these relationships may be useful for informing personalized intervention development.

Results: To address this need, we evaluated 41 different cell type frequencies by mass cytometry and identified their relationships with aging and CMV seropositivity. Analyses were done using 60 healthy individuals, including 23 monozygotic twin pairs, categorized into young (12-31 years) and middle-aged (42-59years). Aging and CMV discordance were associated with increased immune diversity between monozygotic twins overall, and particularly strongly in various T cell populations. Notably, we identified 17 and 11 cell subset frequencies as relatively influenced and uninfluenced by non-heritable factors, respectively, with results that largely matched those from studies on older-aged cohorts. Next, CD4+ T cell frequency was shown to diverge with age in twins, but with lower slope than in demographically similar non-twins, suggesting that much inter-individual variance in this cell type can be attributed to interactions between genetic and environmental factors. Several cell frequencies previously associated with memory inflation, such as CD27- CD8+ T cells and CD161+CD4+ T cells, were positively correlated with CMV seropositivity, supporting findings that CMV infection may incur rapid aging of the immune system.
\end{abstract}

Conclusions: Our study confirms previous findings that aging, even within a relatively small age range and by midadulthood, and CMV seropositivity, both contribute significantly to inter-individual immune diversity. Notably, we identify several key immune cell subsets that vary considerably with aging, as well as others associated with memory inflation which correlate with CMV seropositivity.

Keywords: Mass cytometry (CyTOF), Monozygotic twins, Aging, Cytomegalovirus, Human immunology

\footnotetext{
*Correspondence: sandra.andorf@cchmc.org

'Sean N. Parker Center for Allergy and Asthma Research, Stanford University

School of Medicine, Stanford, CA, USA

${ }^{5}$ Department of Pediatrics, University of Cincinnati College of Medicine,

Cincinnati, OH, USA

Full list of author information is available at the end of the article
}

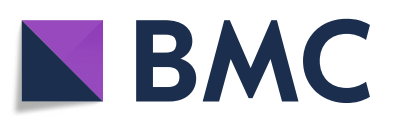

(c) The Author(s). 2021 Open Access This article is licensed under a Creative Commons Attribution 4.0 International License, which permits use, sharing, adaptation, distribution and reproduction in any medium or format, as long as you give appropriate credit to the original author(s) and the source, provide a link to the Creative Commons licence, and indicate if changes were made. The images or other third party material in this article are included in the article's Creative Commons licence, unless indicated otherwise in a credit line to the material. If material is not included in the article's Creative Commons licence and your intended use is not permitted by statutory regulation or exceeds the permitted use, you will need to obtain permission directly from the copyright holder. To view a copy of this licence, visit http://creativecommons.org/licenses/by/4.0/ The Creative Commons Public Domain Dedication waiver (http://creativecommons.org/publicdomain/zero/1.0/) applies to the data made available in this article, unless otherwise stated in a credit line to the data. 


\section{Introduction}

The human immune system has been well known to vary considerably among individuals. Even seemingly minor differences between individuals in immune phenotype may be significant in determining relative susceptibility to both pathogenic and autoimmune diseases, as well as responsiveness to less robust drugs and vaccines [1-4]. Deeper insights into the causes of immune variance are essential for producing better therapeutics for immunity-mediated disorders, especially the ones that vary in prevalence or phenotype [5].

In order to improve understanding of immune variation, many studies have shown that, while much of immune diversity can be attributed to both heritable and non-heritable factors, non-heritable factors were often dominant in their influence [4, 6, 7]. Monozygotic (MZ) and dizygotic twins are often utilized in such studies [811]. One twin-study conducted by our group [12] explored the influence of aging and human cytomegalovirus (CMV) infection on immune phenotype, and found that they both account for an especially high proportion of overall immune variance. These results were supported by both previous and more recent literature [6, 13-16]. However, the extent to which non-heritable factors impact even large categories of immune cells are still under significant debate. For instance, one 2017 study on 497 female twins (aged 41-77 years) reported that inter-individual variance in adaptive immune cell diversity and activity (e.g. CD4+, CD8+ T cells) is more genetically dependent than innate immune cells (e.g. monocytes, Natural Killer T (NKT) cells) [17]. Contrastingly, another 2018 study on 1000 unrelated Western Europeans [18] found the opposite - that adaptive cells phenotypes are actually less genetically dependent than innate cell phenotypes. Thus, more information is needed about the relative contributions of genetic and non-heritable factors to the inter-individual variance for specific cell types. Such data would give broad guidance to future studies seeking to identify therapeutic targets, especially in conjunction with results from previous studies identifying immune cell frequency markers indicative of disease risk [19].

In this study, we explore the immune correlates of two major non-heritable factors: aging and human CMV seropositivity. Aging is well known to have a broad impact on immune system parameters, both through the inherent process of human development and through accumulated exposure to environmental factors $[6,12,15$, 20-22]. However, much of the literature regarding immune aging, including that published by our own group, concerns differences between young and much older (often 60 years or older) individuals [12, 19, 23], as they begin to exhibit physiological symptoms of immunosenescence $[24,25]$. As a result, immune composition changes that accompany mid-adulthood (ages 40-60) are not well characterized. Studying the effects of aging on immune diversity in such middle-aged individuals would evaluate the extent to which immune aging trends previously identified in senescent individuals can already be detected by mid-adulthood, and potentially uncover new trends unidentified by previous studies. Notably, one recent study, in defining a metric of immune aging (IMM-AGE) based on longitudinal data, determined 33 cell subsets that were significantly different between young (ages 20-31) and old (aged 60-96) individuals [19]. Within these 33 cell subsets, 11 continued longitudinal dynamics within the old individuals, while 11 exhibited no significant longitudinal change with aging within either young or old individuals. These results support that significant cell compositional changes likely do occur during mid-adulthood.

Human CMV is a prevalent latent virus that has been found to shape significant portions of the immune system, altering the frequency, phenotype, and potential function of important immune cell groups [26-32]. The underlying mechanisms behind these relationships are not well studied, but suspected to be a result of memory inflation pathways $[27,33,34]$. Notably, the postinfection expansion of CMV-specific memory $\mathrm{T}$ cell populations has been hypothesized to have several detrimental effects, including accelerated immune aging and decreased $\mathrm{T}$ cell repertoire diversity, in even immunocompetent individuals [16]. These effects have been studied in mice, with results indicating that high CMV doses can impair heterologous anti-viral immunity over time $[35,36]$. In another study, CMV seropositivity was significantly correlated with PCA-derived metrics characteristic of immune aging, later used as a basis for positively predicting all-cause human mortality [19]. Contrastingly, other studies have found that CMV may have positive effects to immunocompetent hosts as well, through conferring additional protection from this beneficial stimulation of the immune system [37-39]. Notably, one recent study found higher residual protection rates 1.5 years after influenza vaccination in CMV seropositive individuals [40]. Thus, a more thorough understanding of how CMV affects various cell types may lead to important insights for the risks and possibly benefits of latent viruses, informing better prognostic tools [41].

To address the question of immune system diversity based on aging and CMV, we followed up on these previous studies by further studying immune cells using mass cytometry (CyTOF) and comparing middle-aged twins (between 42 and 59 years) with younger twins (up to 31 years). We chose to investigate the effects of aging on immunity within a relatively small age-range, in order to address the aforementioned gap in knowledge. We also investigated the impact of CMV infection, a 
suggested accelerator of immune aging, on immune cell frequencies in this healthy MZ twin population.

\section{Materials and methods Study cohort}

Data from 60 participants (23 MZ twin pairs and 14 singlets) were included in this analysis. Participants were comprised of a subset of the cohort published in Brodin et al. [12]. While we obtained the data directly from the authors, they are also publicly available through ImmPort (http://www.immport.org, IDs: SDY514, SDY515, SDY519) [42-44]. Smoking is known to have significant effects on immune composition [18]. To avoid confounding, smokers identified by the questionnaire were excluded from the participants. Individual participants were between 11.5 and 59 years old, with a median age of 28.6 (Table 1). While age was utilized as a continuous variable for fitting linear models, in the twin correlationrelated analysis, we binarized age of the twins into younger $(n=14$ pairs, $12.5-30.7$ years, median of 23.6) and middle-aged ( $n=9$ pairs, 42.1-59.0 years, median of 48.6). Of the younger MZ twin pairs, 3 were CMV concordant negative, 9 were CMV concordant positive and 2 were discordant for CMV. Of the middle-aged $\mathrm{MZ}$ twin pairs, 5 were CMV concordant negative, 1 was CMV concordant positive and 3 were discordant for CMV.

\section{Immunological assays}

All immunological assays were performed by the Human Immune Monitoring Center (HIMC) at Stanford University. Details are reported in Brodin et al. [12]. In brief, CMV serology was determined using a commercially available ELISA kit (CMV IgG, Gold Standard Diagnostics) as per manufacturer's instructions. PBMCs were analyzed using mass cytometry (CyTOF, Fluidigm) with the antibody panel shown in Supplementary Table 1.
From FCS3.0 files, cell subset frequencies were determined by manual gating (Supplementary Fig. 1 Supplementary Table 2) using FlowJo v9.3 (TreeStar) as also reported in [12]. In our analyses, we represent these cell subset frequencies as percentages with respect to their parent population.

\section{Assessing the effects of non-heritable factors on immune phenotype heritability}

To determine the impacts of age on the variance of immune phenotypes, the twin-twin Spearman's rank correlation coefficients for the frequencies of each cell type, expressed as percentages of parent populations, were compared between groups of young ( $n=14$ pairs) and middle-aged twins ( $n=9$ pairs). Similar comparisons were made between CMV discordant $(-/+, n=5$ pairs $)$ and CMV concordant negative $(-/-, n=8$ pairs) twins to assess the impacts of CMV. For the correlations within the age groups and CMV concordant negative pairs, the calculation was repeated 25 times with a random break up of each twin pair into the two groups to calculate the correlations. The medians of these correlations were reported. Correlation $P$ values were obtained using Spearman's rho statistic (cor.test function in R). For comparison to an older group of twins, we list the Spearman's rank correlations from the group of $\geq 60$ year-old twins (median: 72 years; $n=16$ ) from Fig. $4 \mathrm{~A}$ in Brodin et al. [12].

Although studying Spearman's rank correlations allows for the comparison between age groups, it does not allow the tracking of phenotypes over aging. Thus, to get a more in-depth analysis of the role of aging, we quantified how immunologically "close" each twin pair was using Euclidian distance between cell frequencies, similar to previous approaches at approximating immunological distance [45]. For comparison, this metric was also calculated between demographically similar, non-

Table 1 Study Cohort Demographics

\begin{tabular}{|c|c|c|c|c|c|}
\hline & Total & Young twins & Middle-aged twins & Young singlets & Middle-aged singlets \\
\hline Total participants (MZ twin pairs) & $60(23)$ & $28(14)$ & $18(9)$ & 5 & 9 \\
\hline Female $[n, \%]$ & $39(65 \%)$ & $19(68 \%)$ & $12(67 \%)$ & $3(60 \%)$ & $5(65 \%)$ \\
\hline Age (years) [median, IQR, range] & $28.6,27.0(11.5-59.0)$ & $23.6,9.3(12.5-30.7)$ & $48.6,10.7(42.1-59.0)$ & $15.8,6.3(11.5-22.5)$ & $53.9,4.0(43.9-56.1)$ \\
\hline Caucasian $[\mathrm{n}, \%]^{*}$ & $47(78 \%)$ & $23(82 \%)$ & $11(61 \%)$ & $4(80 \%)$ & $9(100 \%)$ \\
\hline Asian $[n, \%]$ & $10(17 \%)$ & $7(25 \%)$ & $3(17 \%)$ & $0(0 \%)$ & $0(0 \%)$ \\
\hline Black or African American [n, \%] & $5(8 \%)$ & $0(0 \%)$ & $4(22 \%)$ & $1(20 \%)$ & $0(0 \%)$ \\
\hline Other or declined to answer [n, \%] & $8(13 \%)$ & $4(14 \%)$ & $3(17 \%)$ & $1(20 \%)$ & $0(0 \%)$ \\
\hline$C M V+[n, \%]$ & $32(53 \%)$ & $20(71 \%)$ & $5(28 \%)$ & $4(80 \%)$ & $6(67 \%)$ \\
\hline CMV +/+, $n$ twin pairs (\% of MZ pairs) & $10(43 \%)$ & $9(64 \%)$ & $1(11 \%)$ & & \\
\hline CMV -/-, $\mathrm{n}$ twin pairs (\% of $M Z$ pairs) & $8(35 \%)$ & $3(21 \%)$ & $5(56 \%)$ & & \\
\hline CMV +/-, $n$ twin pairs (\% of MZ pairs) & $5(22 \%)$ & $2(14 \%)$ & $3(33 \%)$ & & \\
\hline
\end{tabular}

*Participants could provide several races, so that the numbers add up to more than $100 \%$ 
twin pairs of individuals sampled from the cohort. These non-twin pairs were generated by pairing each individual with a single random sample from the set of participants who shared their twin's CMV status (but was not their twin) and was within $+/-5$ years of age. Since each twin could be matched to between 2 and 15 (median 6) demographically similar participants outside of the twin pair, we conducted randomized non-twin pairing and Euclidean distance calculation 6 times, with medians used for the analyses and plotting. We investigated the distance between pairs in terms of all cell types to examine broad trends from aging across the immune system, as well as for CD4+ and CD8+ T cells to analyze the effects of aging on these major components of immunity.

In order to further determine the effects of CMV discordance on immune diversity, we compared the Euclidean distances across all cell type frequencies between CMV concordant positive, concordant negative, and discordant twins, as well as corresponding demographically similar non-twin pairs. Significant differences in distances were determined through the Wilcoxon rank-sum test.

$P$ values were adjusted for multiple hypothesis testing using the Benjamini and Hochberg approach to control the false discovery rate (FDR) where required [46]. All statistical analyses were performed using $\mathrm{R}$ software (version 3.4.1).

\section{Determination of significant relationships between CMV and cell frequencies}

To quantify directional impacts between CMV infection status and cell frequencies, a mixed model (lmer from package lme4 in R) was used to fit each cell type frequency. For all individuals (including singlets), age, CMV status, and sex, were used as fixed variables, while twin pair origination was used as a random variable. A chi-square test for goodness of fit was used to determine significant differences. $P$ values were adjusted for multiple comparisons using the approach by Benjamini and Hochberg.

\section{Results}

\section{Twin study population and assay data}

Demographic data can be found in Table 1. All participants involved in the study were reported as healthy, without any symptoms of disease. A total of 64 cell types were analyzed. To avoid redundancy, a Spearman's rank correlation filter was applied to the different cell type frequencies. In this step, of pairs of cell types with an absolute Spearman's rank correlation of $\geq 0.9$ between the frequencies, the cell type with the greater absolute Spearman's rank correlation to all other cell types was chosen to be excluded. After the filter was applied, there were 41 cell types remaining (Supplementary Table 2).

\section{Genetically identical twins immunologically diverge from young to middle-aged}

For each cell type, the median of the repeated calculations of the twin-twin rank correlation of the frequencies within both age groups is shown in Fig. 1 (Table 2 for corresponding values of significant [FDR-adjusted $P<$ 0.1 ] correlations). Notably, out of the 41 cell frequencies, 17 were found to be significantly correlated only between younger twins (red dots in Fig. 1), in contrast to 3 significantly correlated only in middle-aged twins (yellow dots in Fig. 1). In particular, CD4+ and CD8+ $\mathrm{T}$ cells with CD94 expression both had much stronger correlations between young than between middle-aged twins, with coefficients of 0.73 and 0.72 in young twins, but were only weakly correlated with coefficients of 0.25 and 0.22 in middle-aged twins, respectively (Table 2). Other cell types only significantly correlated in young twins included NKT cells, several subsets of B cells, and CD27and CD28- CD8+ T cells. Eleven cell types were significantly correlated in both young and middle-aged twins (teal dots in Fig. 1). These include CD4+ T cells, CD8+ T cells, CD94+ NK cells, and regulatory T cells (Tregs). Additionally reported in Table 2 are the twin-twin Spearman's rank correlations for the group of older MZ twin pairs ( $\geq 60$ years) reported in Brodin et al. [12].

The Euclidean distance across all cell frequencies was examined to show immune system trends with aging as a whole (Fig. 2a). Both twin-twin and non-twin immunological distance across all 41 cell frequencies correlated positively with age at slopes of 0.33 and 0.61 , respectively. Interestingly, it was observed that CD4+ T cells diversified at a notably higher rate between non-twins at a slope of 0.23 compared to between MZ twins with a slope of 0.09 (Fig. 2b). In contrast, CD8+ T cells showed a median slope of 0.17 for distance between non-twins but had a comparatively constant distance (slope of 0.01 ) across our studied age range between twins (Fig. 2c).

\section{Human CMV infections contribute significantly to T cell diversification between twins}

It is well known that microbial exposure plays an important role in shaping the composition and function of the immune system [5]. Human CMV, a prevalent latent virus, is one such microbe known to have broad and lasting effects on immune phenotype [12, 27, 28, 47]. In our twin cohort, 5 pairs of CMV discordant (+/-) twins were identified and their twin-twin Spearman's rank correlations across all cell frequencies were compared with all 8 pairs of CMV concordant negative $(-/-)$ twins (Fig. 3, Table 3). Several cell frequencies showed higher correlations in CMV concordant negative twins than CMV discordant twins, supporting previous findings that CMV has a broad impact on the immune system [12]. Various $\mathrm{T}$ cell subsets were especially affected, including 


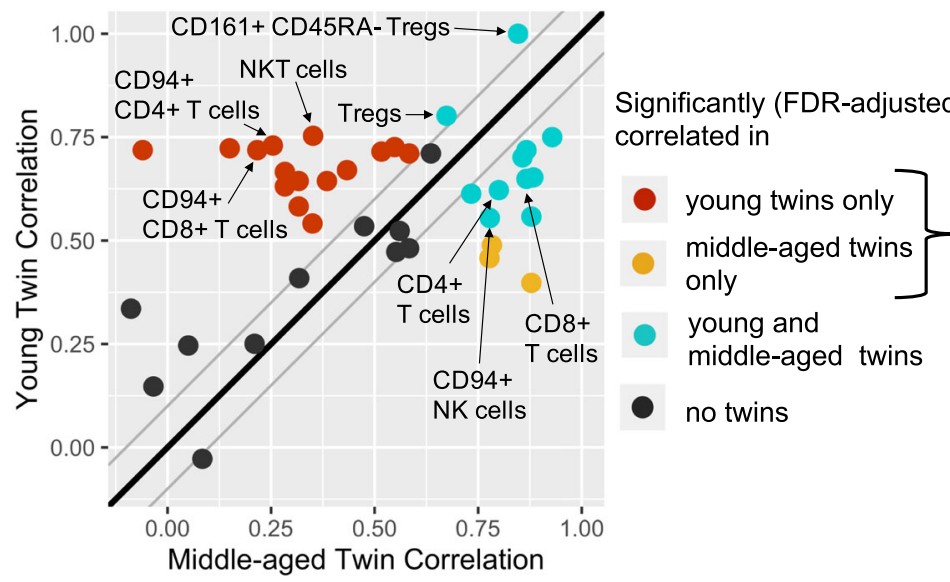

Fig. 1 Spearman's rank correlation (medians of random repeats; see methods) of cell frequencies for young ( $n=14$ pairs) vs. middle-aged ( $n=9$ pairs) twins. Each dot represents one cell type, colored by the significance of that correlation in the younger and middle-aged twin pairs. Black dots denote if no significant correlation was found in either young or middle-aged twins. The thick black line represents values at which the young and middle-aged twins have the exact same Spearman's rank correlation. The upper and lower thin gray lines represent boundaries 0.1 above and below the thick black line

CD4+ T cells, effector memory CD8+ T cells, and CD8+ $\mathrm{T}$ cells, each having strong, significant correlations (FDR-adjusted $P<0.1$ ) in only CMV negative concordant twins. Two cell populations, namely IgD- CD27- B cells and CD28+CD4+ T cells, were significantly correlated between twins in both CMV negative concordant and discordant groups, suggesting these populations are especially stable across persistent viral stimulation.

To further examine the impacts of CMV status on immune cell diversity, both twin-to-twin and demographically similar non-twin Euclidean distances were calculated across all cell types and categorized by individual CMV seropositivity (Fig. 4). There was a significant difference between twin-twin and twin-non-twin distance for all CMV concordant twins $(P<0.01)$, but not between CMV discordant twins $(P=0.55)$. This analysis supports previous findings that CMV seropositivity, although often symptomless, additionally shapes the immune system in many ways.

\section{CMV infection increases anti-inflammatory and viral- specific memory $T$ cell frequencies}

To quantify directional effects, we also looked for significant correlations (FDR-adjusted $P<0.05$ ) between cell frequencies and both aging and CMV. CD94+ CD8+ T cells and CD85j + CD8+ T cells, both cell types associated with inhibition of cytotoxicity [26, 27], were found to have significantly higher frequencies in CMV positive individuals (Fig. 5). CD161+ CD4+ T cells, effector memory CD8+ T cells, and CD27- CD8+ T cells, indicators of long-term viral-specific memory pools [16, 29], were found to have significantly higher frequencies in CMV positive individuals as well.

\section{Discussion}

To further understand the effects of inherited vs noninherited influences on the immune system, we analyzed the impact of age and CMV status on the cellular composition of the immune system in a cohort of $46 \mathrm{MZ}$ twins (23 pairs) in this exploratory, pilot study.

Firstly, we examined the effects of being middle-aged (median 48.6 years) vs younger (median 23.6 years) on cell frequency diversity between healthy MZ twins by Spearman's rank correlation coefficient. A subset (17 out of 41) of the cell frequencies were observed to diverge in the middle-aged MZ twins, but not younger ones. This result supports that aging has a large impact on the variability of several adaptive cell types, many of which have also been found to vary with age by previously published studies $[12,45]$. In a similar analysis by our group [12], we compared young MZ twins ( $\leq 20$ years, median 13.5 ) with older twins ( $\geq 60$ years, median 72 ), and highlighted Tregs as the most extreme example of being very strongly correlated (coefficient 0.78 ) in young twins and not correlated (coefficient 0.24) in the older twins. In this current study, for Treg frequencies we observed a strong correlation for the younger twins (coefficient 0.80 ), but just slightly weaker correlation for the middleaged twins (coefficient 0.67) (Table 2). These results, taken together, are in line with prior studies indicating that changes in Treg frequency occur more dominantly in older adults [48-50]. In the data presented here, 11 out of the 41 cell frequencies were found to have significant correlations between twins of both studied age groups. The cell types were mostly consistent with what was reported as being dominantly controlled by heritable factors when analyzed using a structural equation 
Table 2 Cell Frequencies Significantly Correlated Between Younger and/or Middle-aged Twins

\begin{tabular}{|c|c|c|c|c|c|}
\hline Cell type & $\begin{array}{l}\text { Young twins Spearman's } \\
\text { rank correlation* }\end{array}$ & $\begin{array}{l}\text { Middle-aged twins } \\
\text { Spearman's rank } \\
\text { correlation }\end{array}$ & $\begin{array}{l}\text { Young twins } \\
\text { FDR-adjusted P }\end{array}$ & $\begin{array}{l}\text { Middle-aged twins } \\
\text { FDR-adjusted P }\end{array}$ & $\begin{array}{l}\text { Older twins Spearman's } \\
\text { rank correlation from } \\
\text { Brodin et al. [12] }\end{array}$ \\
\hline IgD+ CD27- B cells & 0.65 & 0.88 & 0.039 & 0.020 & 0.68 \\
\hline lgD- CD27+ B cells & 0.70 & 0.86 & 0.020 & 0.020 & 0.6 \\
\hline IgD- CD27- B cells & 0.72 & 0.87 & 0.020 & 0.020 & 0.56 \\
\hline CD16+ Monocytes & 0.56 & 0.88 & 0.082 & 0.020 & NA \\
\hline CD4+ T cells & 0.62 & 0.80 & 0.046 & 0.039 & 0.76 \\
\hline CD28+ CD4+ T cells & 0.75 & 0.93 & 0.020 & 0.012 & NA \\
\hline CD8+ T cells & 0.65 & 0.87 & 0.039 & 0.020 & 0.68 \\
\hline Effector Memory CD8+ T cells & 0.61 & 0.73 & 0.053 & 0.071 & 0.9 \\
\hline CD94+ NK cells & 0.55 & 0.78 & 0.083 & 0.039 & NA \\
\hline CD161+ CD45RA- Tregs & 1.00 & 0.85 & $<0.001$ & 0.028 & 0.97 \\
\hline Tregs & 0.80 & 0.67 & 0.015 & 0.095 & 0.24 \\
\hline B cells & 0.67 & 0.43 & 0.038 & 0.34 & 0.25 \\
\hline $\operatorname{lgD}+\mathrm{CD} 27+\mathrm{B}$ cells & 0.53 & 0.47 & 0.095 & 0.27 & 0.51 \\
\hline Naïve B cells & 0.67 & 0.28 & 0.039 & 0.52 & 0.85 \\
\hline Transitional B cells & 0.73 & 0.55 & 0.020 & 0.19 & 0.28 \\
\hline Central Memory CD4+ T cells & 0.64 & 0.38 & 0.041 & 0.40 & 0.55 \\
\hline CD94+ CD4+ T cells & 0.73 & 0.25 & 0.020 & 0.56 & NA \\
\hline CD27+ CD4+ T cells & 0.71 & 0.64 & 0.020 & 0.12 & NA \\
\hline CD161+ CD4+ T cells & 0.72 & 0.52 & 0.020 & 0.23 & NA \\
\hline CD161- CD8+ T cells & 0.64 & 0.32 & 0.040 & 0.47 & NA \\
\hline CD27- CD8+ T cells & 0.58 & 0.32 & 0.071 & 0.47 & NA \\
\hline CD28- CD8+ T cells & 0.63 & 0.28 & 0.045 & 0.52 & NA \\
\hline CD94+ CD8+ T cells & 0.72 & 0.22 & 0.020 & 0.63 & NA \\
\hline CD85j + CD8+ T cells & 0.54 & 0.35 & 0.095 & 0.45 & NA \\
\hline Effector CD8+ T cells & 0.72 & 0.15 & 0.020 & 0.74 & 0.28 \\
\hline CD161- CD45RA+ Tregs & 0.72 & -0.06 & 0.020 & 0.15 & 0.66 \\
\hline CD161+ NK cells & 0.71 & 0.58 & 0.020 & 0.17 & NA \\
\hline NKT cells & 0.75 & 0.35 & 0.020 & 0.45 & 0.7 \\
\hline Lymphocytes & 0.49 & 0.78 & 0.14 & 0.044 & 0.8 \\
\hline CD85j- CD4+ T cells & 0.40 & 0.88 & 0.23 & 0.020 & NA \\
\hline Effector CD4+ T cells & 0.46 & 0.78 & 0.19 & 0.039 & 0.7 \\
\hline
\end{tabular}

* Medians of the repeated calculations of Spearman's rank correlation coefficients are reported (see methods)

Statistically significant results (FDR-adjusted $\mathrm{P}<0.1)$ are bolded

modeling approach including dizygotic twins to estimate heritability [12]. All of these cell types, except Tregs, for which correlation values were reported in Brodin et al. [12] had also for the older twin population Spearman's rank correlations of at least 0.56 . Overall, these results support that, between pre-senescent individuals, immune cell composition tends to diverge alongside aging in some areas but remain stable in others. Specifically, we highlighted 17 and 11 cell subset frequencies as relatively influenced and uninfluenced by non-heritable factors, respectively. These 17 cell subsets that diverged in middle-aged MZ twins are more likely to be affected by environmental or lifestyle factors and are thus particularly interesting targets for future precision health studies, especially those cell types previously associated with risk factors. For instance, CD28- CD8+ T cell and B cell frequencies were also major components of the cellbased IMM-AGE score, whose approximation was found to be a meaningful predictor of all-cause mortality in a dataset comprised of both middle aged and older individuals [19]. As mentioned in the introduction, 11 cell subsets were identified in that study as showing a 


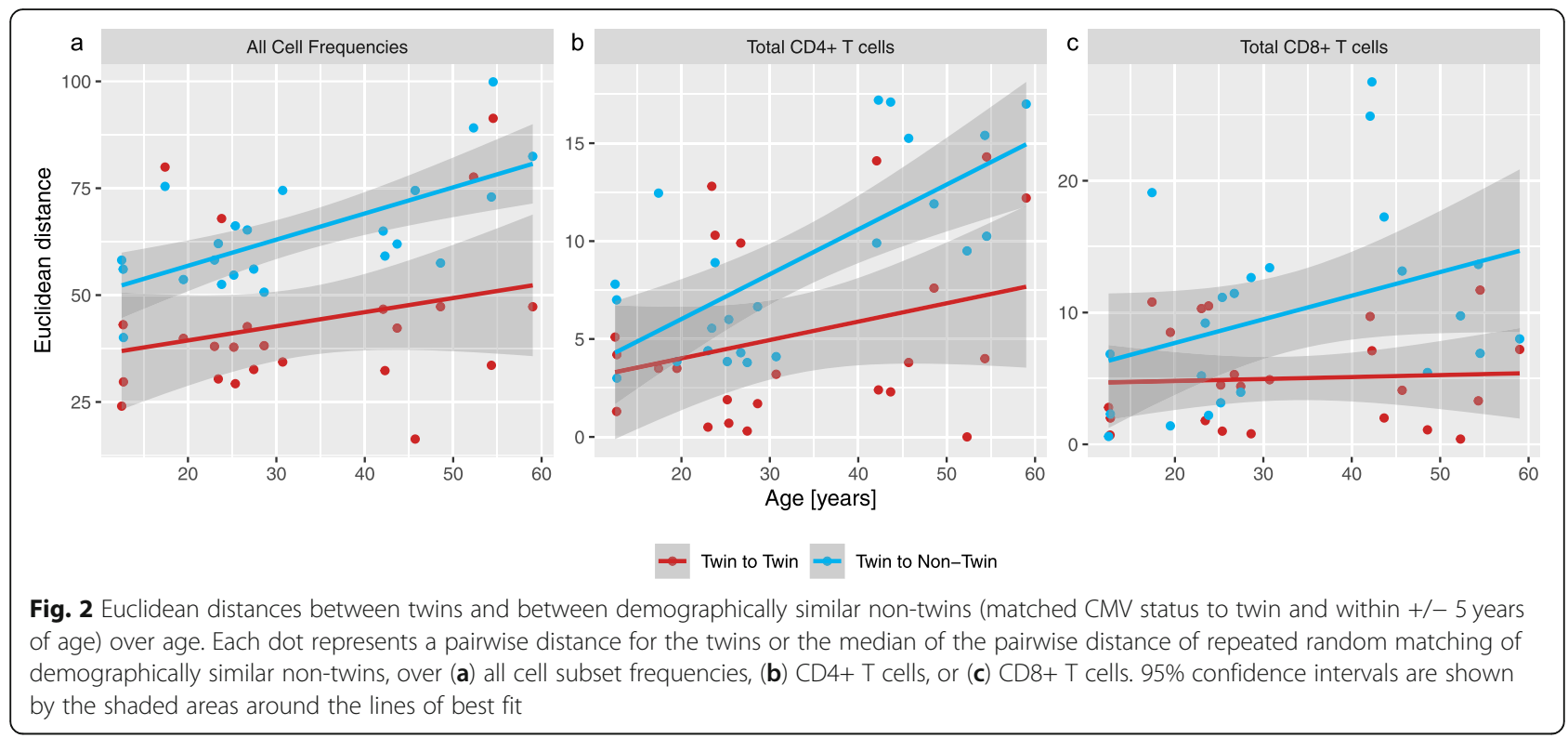

significant difference between the young and old individuals and as demonstrating continued longitudinal changes in the old individuals. Interestingly, 7 of these cell subsets were also analyzed in our work and 4 (B cells, CD161- CD45RA+ Treg, CD28- CD8+ T cells, Effector CD8+ $\mathrm{T}$ cells) showed a significant correlation in the younger twins but not in the middle-aged twins. This could suggest that non-heritable factor driven changes of these cell subsets start at early mid-age and continue into older adulthood. To make rigorous conclusions, future longitudinal studies spanning mid-age and older individuals should investigate the dynamics of these cell subsets.
In interpreting our results, several limitations should be kept in mind. First, we utilized previously generated data in this pilot study and the sample size is limited. As a result, many of the discussed findings are preliminary and should be tested in a larger cohort. Furthermore, younger twins often either cohabitate or have lived apart for a shorter period of time, confounding these findings due to more recently shared environmental exposures. Lastly, the participants in this study were mostly Caucasian, making the presented results strongly biased towards this ethnicity.

To calculate twin-twin cell frequency correlations within an age group, we first randomly assigned each

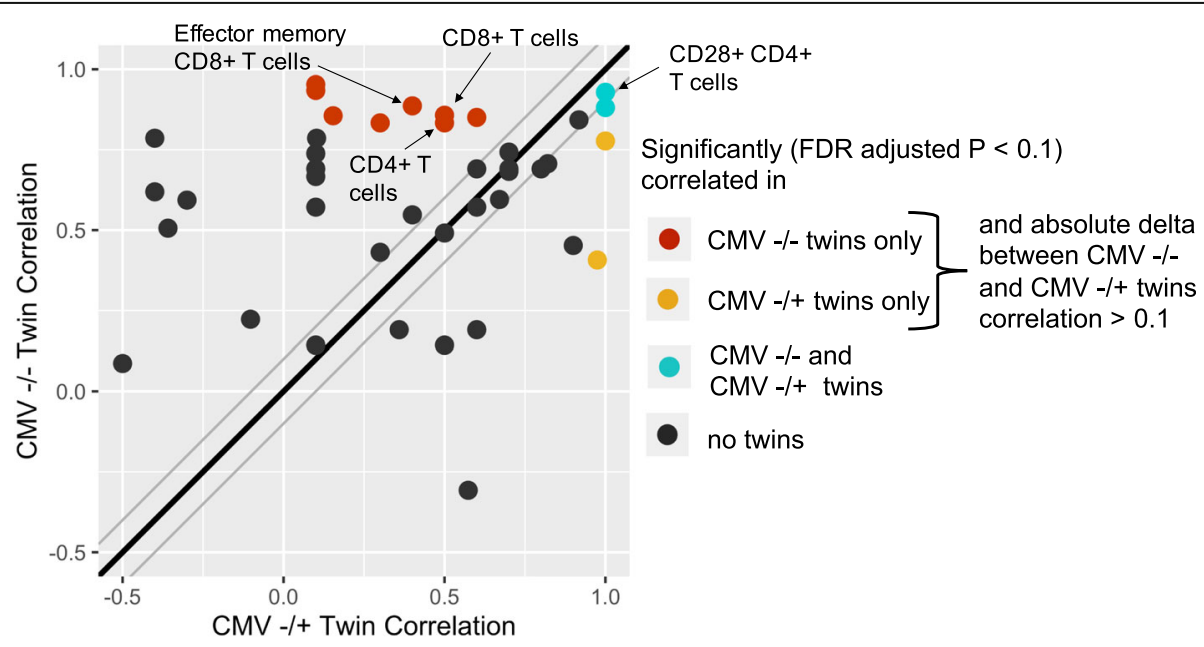

Fig. 3 Spearman's rank correlation plot of cell frequencies for CMV concordant negative ( $n=8$, medians of random repeats reported; see methods) vs. CMV discordant $(n=5)$ twins. Each dot represents one cell type. The thick black line represents values at which both $C M V-/+$ and $-/-$ twins have the exact same Spearman's rank correlation. The upper and lower thin gray lines represent boundaries 0.1 above and below the thick black line 
Table 3 Cell Frequencies Significantly Correlated Between CMV $-/-(n=8$ pairs) and/or CMV $-/+(n=5$ pairs) Twins

\begin{tabular}{|c|c|c|c|c|}
\hline Cell type & $\begin{array}{l}\text { CMV -/- twins Spearman's } \\
\text { rank correlation* }\end{array}$ & $\begin{array}{l}\text { CMV }-/+ \text { twins Spearman's } \\
\text { rank correlation }\end{array}$ & $\begin{array}{l}\text { CMV -/- twins } \\
\text { FDR-adjusted P }\end{array}$ & $\begin{array}{l}\text { CMV -/+ twins } \\
\text { FDR-adjusted P }\end{array}$ \\
\hline IgD- CD27- B cells & 0.88 & 1.00 & 0.077 & 0.091 \\
\hline CD28+ CD4+ T cells & 0.93 & 1.00 & 0.061 & 0.091 \\
\hline $\operatorname{lgD}+$ CD27- B cells & 0.95 & 0.10 & 0.047 & 0.95 \\
\hline IgD- CD27+ B cells & 0.83 & 0.30 & 0.085 & 0.81 \\
\hline Transitional B cells & 0.85 & 0.60 & 0.077 & 0.56 \\
\hline CD4+ T cells & 0.83 & 0.50 & 0.091 & 0.66 \\
\hline CD85j- CD4+ T cells & 0.93 & 0.10 & 0.047 & 0.95 \\
\hline CD8+ T cells & 0.86 & 0.50 & 0.085 & 0.66 \\
\hline Effector memory CD8+ T cells & 0.89 & 0.40 & 0.069 & 0.69 \\
\hline CD161+ CD45RA- Tregs & 0.84 & 0.92 & 0.078 & 0.12 \\
\hline NKT cells & 0.86 & 0.15 & 0.077 & 0.92 \\
\hline CD94+ NK cells & 0.41 & 0.97 & 0.55 & 0.077 \\
\hline Tregs & 0.78 & 1.00 & 0.12 & 0.091 \\
\hline
\end{tabular}

* For the CMV concordant negative twins, medians of the repeated calclations of Spearman's rank correlations are reported (see methods)

Statistically significant results (FDR-adjusted $\mathrm{P}<0.1$ ) are bolded

member of every eligible twin pair into either the "twin A" or "twin B" group. However, especially given the small sample size, exactly how twins were divided into these two groups may contribute unnecessary variance. To mitigate this variance, we repeated this split of twins randomly 25 times and recorded not only the median Spearman's rank correlation and $P$ value as reported in the results, but also the interquartile range (IQR) of the correlation coefficients of the 25 repeats per cell type per age group. Across the cell types, the IQR of the correlation coefficients in the younger twins ranged from 0 to 0.14 and in the middle-aged twins from 0.012 to 0.19 . This variability can be attributed to the small sample size and needs to be considered when interpreting our results.

As an additional approach to quantifying immune variance, distances were calculated both between twins and between non-twins using a similar Euclidean approach as previously done to approximate immunological closeness (Fig. 2) [45]. Importantly, non-twin pairs were generated by matching individuals to a randomly sample from the set of participants similar to their twin, as

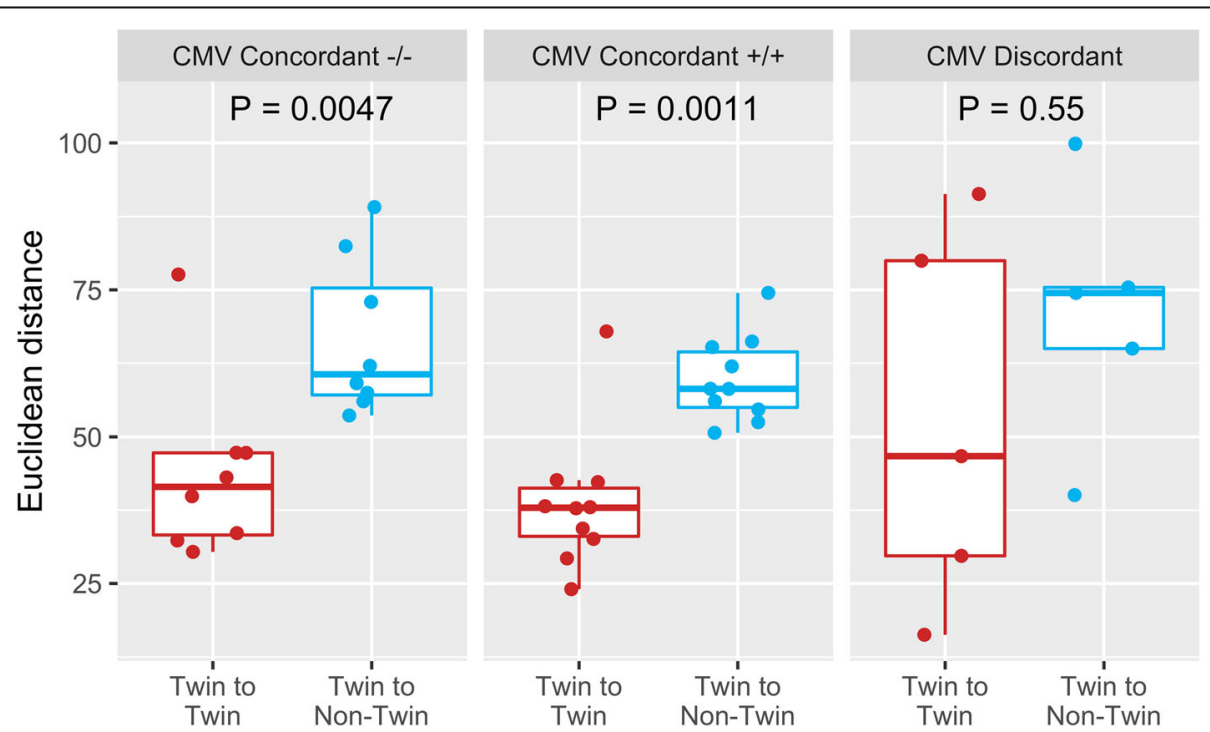

Fig. 4 Euclidean distance for all cell subset frequencies between twin and demographically similar non-twin pairs (median distance for 6 repeated random matching of demographically similar individuals), stratified by pairwise CMV seropositivity. Each dot represents the immunological distance, taking into account all cell frequencies, between a twin or non-twin pairing. P values by Wilcoxon rank sum tests 


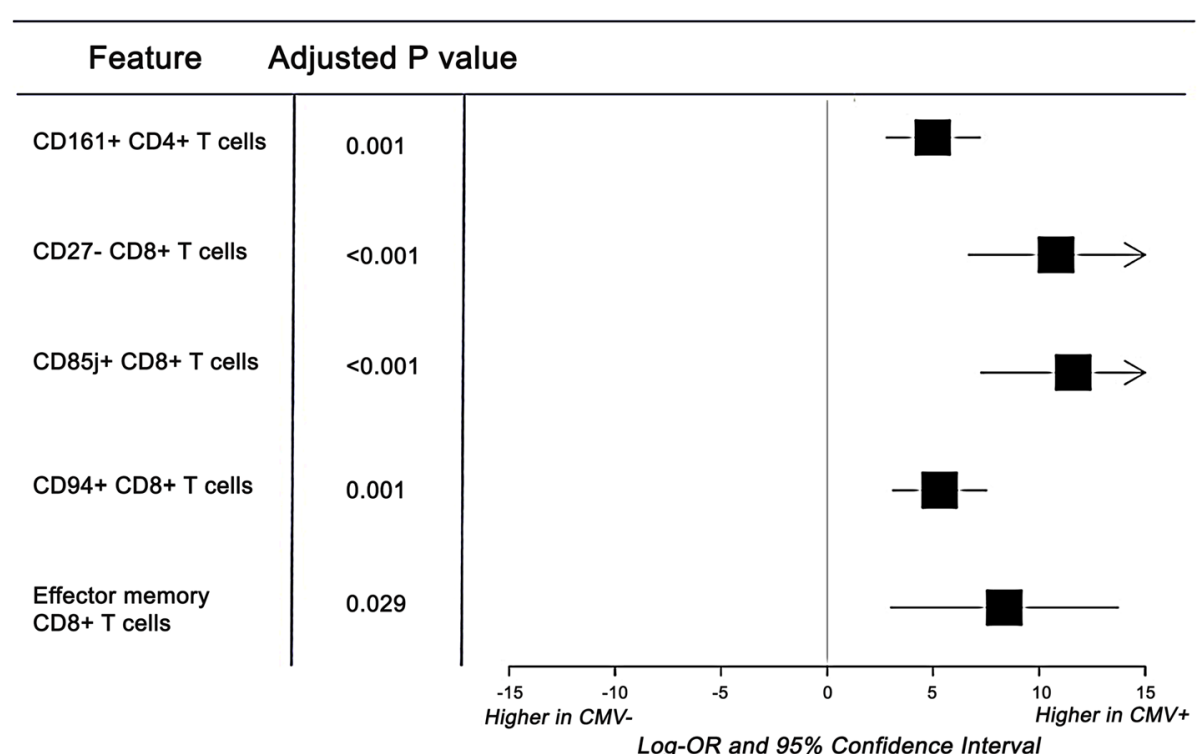

Fig. 5 Cell frequencies significantly correlated with CMV positivity in our cohort. Each row in the forest plot represents a cell subset for which the frequency was found to be significantly correlated (FDR-adjusted $P$ value $<0.05$ ) with CMV positivity within the cohort (after adjustment for age, sex and twin pair (or singlet) origin). The log odds ratio using the features of interest to predict CMV positivity are also shown as measurements of effect size, along with corresponding confidence intervals

defined by age and CMV seropositivity. Interestingly, we observed that $\mathrm{CD} 4+\mathrm{T}$ cells diversified over age between twins as well as non-twins; however, we found a higher rate of divergence in the non-twins, suggesting that much of inter-individual variance within this cell type may be attributed to interactions between factors regulated by environment and factors driven by genetics. Note that while our results highlight differing rates of divergence in the immune system between MZ twins and non-twins, to estimate actual heritability, the inclusion of dizygotic twins is needed, as was done in Mangino et al. [17]. Previous work in this area has shown conflicting results, which may stem from the highly heterogenous consistency of $\mathrm{CD} 4+\mathrm{T}$ cell populations. For instance, while Brodin et al. [12] and Patin et al. [18] identified $\mathrm{CD} 4+\mathrm{T}$ cell proportions as non-genetically determined, Mangino et al. found $\mathrm{CD} 4+\mathrm{T}$ cell proportions to be more influenced by genetics [17]. In contrast to $\mathrm{CD} 4+\mathrm{T}$ cells, our data for $\mathrm{CD} 8+\mathrm{T}$ cells showed no increase of distance between twins over age (Fig. 2c). Prior findings showed CD8+ T cell population frequencies as being most likely more genetically determined $[12,18,51]$. Overall, genetically identical twins might have the tendency to react similarly to accumulated environmental exposure, causing their rate of immune divergence to be lower than that of non-twins but nevertheless showing an increased distance over age. Thus, our results support that gene-environment interactions play important roles in determining immune system composition over time, and specifically within $\mathrm{T}$ cell populations. To make rigorous conclusions in this area, both additional multi-omics data and larger sample sizes including MZ and dizygotic twins are needed, especially since we observed large variations in distances among twin pairs.

CMV, one of the most common viral infections in the world, and recently a suspect in causing significant immune debilitations $[16,30,52]$, was another focus of our study. Our results suggest that CMV discordance increases immune diversity between twins (Fig. 3), showing that a large set of immune cells are impacted by CMV, as previously publications have found [26, 28, 32]. Twin-twin averaged immunological distances were significantly lower than non-twin distances for both CMV concordant positive and CMV concordant negative twins, but not between CMV discordant twins (Fig. 4). However, these limited results should only be interpreted as possible trends because of the low sample size $(n=5)$ of CMV discordant twin pairs in our cohort.

When comparing the results of the correlation analyses based on age and CMV, NKT cells and transitional $\mathrm{B}$ cells were found to be significantly correlated between young twins but not in middle-aged twins and were also significantly correlated in CMV negative concordant but not CMV discordant twins. Recent publications investigating the immunogenic effects of CMV have demonstrated similar results, suggesting that CMV may accelerate aging in many areas of immune phenotype [45]. Due to sample size limitations, we were unable to test this hypothesis more strongly through directly 
comparing cell frequency correlations between young CMV discordant twins and between older CMV concordant twins. A previous study suggested that the immune response to CMV may also be genetically influenced [53], underscoring the need for such studies in larger CMV-related cohorts including $\mathrm{MZ}$ and dizygotic twins.

Furthermore, we found several cell types to be significantly correlated with CMV seropositivity in the overall cohort (Fig. 5). To begin, one other study also examined the association between CD161+CD4+ T cells and CMV seropositivity, finding no difference in their frequency between CMV+ and CMV- young individuals [54]. Contrastingly, we found that CMV seropositivity increases CD161+ CD4+ T cell levels in our cohort, which consists of both young and middle-aged individuals, while controlling for age. The previous study also found that CD161+ CD4+ T cells decrease in age within CMV seropositive individuals. Together, these results suggest that age and CMV seropositivity potentially both impact CD161+ CD4+ T cell levels. As this cell subset has been found to contribute to long-term persistence of virus-specific memory $\mathrm{CD} 4+\mathrm{T}$ cells, future studies in this area may reveal more insights about how different conditions affect immune memory [29]. Next, our finding of significantly greater levels of CD85j $+\mathrm{CD} 8+\mathrm{T}$ cells and CD94+ CD8+ T cells in CMV positive individuals than in CMV negative participants is in line with prior findings $[26,27,55]$. The precise role of CD85j and CD94, which are traditionally NK receptors, in the CMV-initiated $\mathrm{T}$ cell response has yet to be elucidated [56]. One study hypothesized that CD85j plays an important role in CMV-mediated $\mathrm{T}$ cell dysfunction - as $\mathrm{CD} 85 \mathrm{j}$ is induced by persistent antigen exposure, inhibits effector function by blocking interferon production, and can be activated by the CMV MHC homolog UL18 [55]. Lastly, we found significantly higher levels of CD27$\mathrm{CD} 8+\mathrm{T}$ cells and effector memory CD8+ $\mathrm{T}$ cells in CMV positive participants, which were previously characterized as memory inflation phenotypes and have been previously observed in both mice and humans [26, 27, 57, 58]. These results support prior hypotheses that, through persistent and specific immune responses that dominate existing memory pools, CMV accelerates immune aging and leads to increased immune dysfunction $[14,16,52,59]$. One study showed that upregulation of these cell types, alongside other late-differentiated CD4+ cells, in CMV-positive individuals were influenced by genetic factors as well [53]. In the future, further multiomics analyses may provide more useful insights for the implications of CMV infection on an individual's immune composition.

Lastly, while CMV is the most studied virus in relation to immunosenescence, studies suggest that more viruses as well as remnants of ancient retroviral infections in our genome potentially affect immune aging, as discussed in a recent review [60]. Notably, it is estimated that adults are infected by $5-10$ persistent/chronic viruses, many of which were also associated with immunosenescence [52, 61]. Future studies exploring factors associated with immune aging should therefore include these factors in addition to CMV.

\section{Conclusions}

Our exploratory study finds that aging, even within our relatively small age range, and CMV seropositivity are major sources of immune variance. Notably, we identified 17 cell frequencies which significantly correlate between younger twins, but not middle-aged ones indicating that these subsets are most susceptible to influence by environmental factors. These cell frequencies were largely also identified in similar studies on young vs. older individuals, suggesting that for this subset of cell types, this effect of increased immune diversity between monozygotic twins is already notable within a relatively small age range and by mid-adulthood. In the future, the specific origins and implications of variance in these subsets will likely be beneficial to study, such as for developing more personalized immunological therapies and for studying immunotoxic effects of environmental factors. We also highlight several cell subsets, many previously associated with the phenomenon of memory inflation, to be correlated with CMV seropositivity. This evidence supports previous findings that CMV may reduce $\mathrm{T}$ cell diversity, potentially leading to decreased adaptive immune function.

\section{Supplementary Information}

The online version contains supplementary material available at https://doi. org/10.1186/s12979-021-00216-1.

Additional file 1: Supplementary Fig. 1. Manual gating schema using the FlowJo v9.3 software (TreeStar, Inc) for one representative FCS3.0-file generated by Mass Cytometry (CyTOF). Supplementary Table 1. CyTOF panel used for data acquisition at the Human Immune Monitoring Center (HIMC) at Stanford University. All antibodies were conjugated in house. Supplementary Table 2. Manual gating strategy for the 41 cell types remaining after filtering for our analysis.

\section{Abbreviations}

CMV: cytolomegavirus; FDR: false discovery rate; IQR: interquartile range; MZ: monozygotic; NKT: Natural Killer T; Tregs: regulatory T cells

\section{Acknowledgments}

The authors thank Mike Leipold for mass cytometry analyses, Yael Rosenberg-Hasson for CMV ELISAs, Manisha Desai for input on the statistical analysis, as well as Xiaoying Zhou and Monali Manohar for input about immunological details.

\section{Authors' contributions}

ZY and SA wrote the manuscript with assistance from HM, KN and PB. ZY and SA performed data analysis. KN, HM, PM and MD conceived of and assisted with design of the project. HM, PB, UN, SL, MD and KN assisted with 
interpretation of results. KN was PI of the grant that funded the study (R21). The authors read and approved the final manuscript.

\section{Funding}

Our work was funded by the R01HL118612, R21ES022153, 5U19AI057229 and S10RR027582 National Institutes of Health $(\mathrm{NIH})$ grants; and the Sean N. Parker Center for Allergy and Asthma Research at Stanford University.

\section{Availability of data and materials}

The dataset supporting the conclusions of this article is available in ImmPort, [http://www.immport.org, IDs: SDY514, SDY515, SDY519].

\section{Ethics approval and consent to participate}

We used a Stanford IRB approved protocol to collect all the samples and perform the studies in a deidentified fashion as per CFR/GCP (code of federal regulation/good clinical practice) guidelines.

\section{Consent for publication}

Not applicable.

\section{Competing interests}

Dr. Nadeau reports grants from National Institute of Allergy and Infectious Diseases (NIAID), Food Allergy Research \& Education (FARE), End Allergies Together (EAT), Allergenis, and Ukko Pharma; Grant awardee at NIAID, National Institute of Environmental Health Sciences (NIEHS), National Heart, Lung, and Blood Institute (NHLBI), and the Environmental Protection Agency (EPA); is involved in Clinical trials with Regeneron, Genentech, Almmune Therapeutics, DBV Technologies, AnaptysBio, Adare Pharmaceuticals, and Stallergenes-Greer; Research Sponsorship by Novartis, Sanofi, Astellas, Nestle; Data and Safety Monitoring Board member at Novartis and NHLBI; Cofounded Before Brands, Alladapt, ForTra, and Iggenix; Chief Intellectual Office at FARE, Director of the World Allergy Organization (WAO) Center of Excellence at Stanford, Personal fees from Regeneron, Astrazeneca, ImmuneWorks, and Cour Pharmaceuticals; Consultant and Advisory Board Member at European Academy of Allergy and Clinical Immunology (EAACI) Research and Outreach Committee, Ukko, Before Brands, Alladapt, IgGenix, Probio, Vedanta, Centecor, Seed, Novartis, NHBLI, EPA, National Scientific Committee of Immune Tolerance Network (ITN) and NIH Programs; US patents for basophil test, multifood immunotherapy and prevention, monoclonal antibody from plasmablasts, and a device for diagnostics. The remaining authors declare no relevant competing interests.

\section{Author details}

'Sean N. Parker Center for Allergy and Asthma Research, Stanford University School of Medicine, Stanford, CA, USA. ${ }^{2}$ Institute for Immunity, Transplantation and Infection, Stanford University School of Medicine, Stanford, CA, USA. ${ }^{3}$ Science for Life Laboratory, Department of Women's and Children's Health, Karolinska Institutet, Stockholm, Sweden. ${ }^{4}$ Division of Infection Control and Environmental Health, Norwegian Institute of Public Health, Oslo, Norway. ${ }^{5}$ Department of Pediatrics, University of Cincinnati College of Medicine, Cincinnati, OH, USA. ${ }^{6}$ Divisions of Biomedical Informatics and Allergy \& Immunology, Cincinnati Children's Hospital Medical Center, Cincinnati, OH, USA.

\section{Received: 10 October 2020 Accepted: 8 January 2021}

\section{Published online: 18 January 2021}

\section{References}

1. Germain RN, Schwartzberg PL. The human condition: an immunological perspective. Nat Immunol. 2011;12:369-72.

2. Steinman RM, Mellman I. Immunotherapy: bewitched, bothered, and bewildered no more. Science. 2004;305:197-200.

3. Roederer M, Quaye L, Mangino M, Beddall MH, Mahnke Y, Chattopadhyay P, et al. The genetic architecture of the human immune system: a bioresource for autoimmunity and disease pathogenesis. Cell. 2015;161:387-403.

4. Haralambieva IH, Painter SD, Kennedy RB, Ovsyannikova IG, Lambert ND, Goergen KM, et al. The impact of immunosenescence on humoral immune response variation after influenza a/H1N1 vaccination in older subjects. PLoS One. 2015;10:e0122282.

5. Brodin P, Davis MM. Human immune system variation. Nat Rev Immunol. 2017:17:21-9.
6. Carr EJ, Dooley J, Garcia-Perez JE, Lagou V, Lee JC, Wouters C, et al. The cellular composition of the human immune system is shaped by age and cohabitation. Nat Immunol. 2016;17:461-8.

7. Cheung P, Vallania F, Warsinske HC, Donato M, Schaffert S, Chang SE, et al. Single-Cell Chromatin Modification Profiling Reveals Increased Epigenetic Variations with Aging. Cell. 2018;173:1385-1397.e14.

8. Steves CJ, Spector TD, Jackson SHD. Ageing, genes, environment and epigenetics: what twin studies tell us now, and in the future. Age Ageing. 2012:41:581-6.

9. Hall M, Ahmadi K, Norman P, Snieder H, MacGregor A, Vaughan R, et al. Genetic influence on peripheral blood T lymphocyte levels. Genes Immun. 2000;1:423-7.

10. Bunning BJ, Contrepois K, Lee-McMullen B, Dhondalay GKR, Zhang W, Tupa $D$, et al. Global metabolic profiling to model biological processes of aging in twins. Aging Cell. 2020;19:e13073.

11. Craig JM, Calais-Ferreira L, Umstad MP, Buchwald D. The value of twins for health and medical research: a third of a century of Progress. Twin Res Hum Genet. 2020;23:8-15

12. Brodin $\mathrm{P}$, Jojic V, Gao T, Bhattacharya S, Angel CJL, Furman D, et al. Variation in the human immune system is largely driven by non-heritable influences. Cell. 2015:160:37-47.

13. Rölle A, Brodin P. Immune adaptation to environmental influence: the case of NK cells and HCMV. Trends Immunol. 2016;37:233-43.

14. Sylwester AW, Mitchell BL, Edgar JB, Taormina C, Pelte C, Ruchti F, et al. Broadly targeted human cytomegalovirus-specific CD4 + and CD8 + T cells dominate the memory compartments of exposed subjects. J Exp Med. 2005;202:673-85.

15. Liston A, Carr EJ, Linterman MA. Shaping variation in the human immune system. Trends Immunol. 2016;37:637-46.

16. Jergović M, Contreras NA, Nikolich-Žugich J. Impact of CMV upon immune aging: facts and fiction. Med Microbiol Immunol. 2019;208:263-9.

17. Mangino M, Roederer M, Beddall MH, Nestle FO, Spector TD. Innate and adaptive immune traits are differentially affected by genetic and environmental factors. Nat Commun. 2017:8:13850.

18. Patin E, Hasan M, Bergstedt J, Rouilly V, Libri V, Urrutia A, et al. Natural variation in the parameters of innate immune cells is preferentially driven by genetic factors. Nat Immunol. 2018;19:302-14.

19. Alpert A, Pickman $Y$, Leipold $M$, Rosenberg-Hasson $Y$, Ji X, Gaujoux R, et al. A clinically meaningful metric of immune age derived from highdimensional longitudinal monitoring. Nat Med. 2019;25:487-95.

20. Weiskopf D, Weinberger B, Grubeck-Loebenstein B. The aging of the immune system. Transpl Int. 2009;22:1041-50.

21. Yan J, Greer JM, Hull R, O'Sullivan JD, Henderson RD, Read SJ, et al. The effect of ageing on human lymphocyte subsets: comparison of males and females. Immun Ageing. 2010;7:4

22. Simon AK, Hollander GA, McMichael A. Evolution of the immune system in humans from infancy to old age. Proc R Soc B Biol Sci. 2015:282:20143085.

23. Nikolich-Žugich J. The twilight of immunity: emerging concepts in aging of the immune system. Nat Immunol. 2018:19:10-9.

24. Kline KA, Bowdish DME. Infection in an aging population. Curr Opin Microbiol. 2016:29:63-7.

25. Denkinger MD, Leins H, Schirmbeck R, Florian MC, Geiger H. HSC aging and senescent immune remodeling. Trends Immunol. 2015;36:815-24.

26. van Stijn A, Rowshani AT, Yong SL, Baas F, Roosnek E, ten Berge IJM, et al. Human cytomegalovirus infection induces a rapid and sustained change in the expression of NK cell receptors on CD8+ T cells. J Immunol. 2008;180: 4550-60.

27. Kim J, Kim A-R, Shin E-C. Cytomegalovirus infection and memory T cell inflation. Immune Netw. 2015;15:186-90.

28. Miller-Kittrell M, Sparer TE. Feeling manipulated: cytomegalovirus immune manipulation. Virol J. 2009;6:4.

29. Alsuliman A, Muftuoglu M, Khoder A, Ahn YO, Basar R, Verneris MR, et al. A subset of virus-specific CD161+T cells selectively express the multidrug transporter MDR1 and are resistant to chemotherapy in AML. Blood. 2017 129:740-58

30. Savva GM, Pachnio A, Kaul B, Morgan K, Huppert FA, Brayne C, et al. Cytomegalovirus infection is associated with increased mortality in the older population. Aging Cell. 2013:12:381-7.

31. Simanek AM, Dowd JB, Pawelec G, Melzer D, Dutta A, Aiello AE. Seropositivity to cytomegalovirus, inflammation, all-cause and cardiovascular disease-related mortality in the United States. PLoS One. 2011;6:e16103. 
32. Nikolich-Žugich J, Čicin-Šain L, Collins-McMillen D, Jackson S, Oxenius A, Sinclair J, et al. Advances in cytomegalovirus (CMV) biology and its relationship to health, diseases, and aging. GeroScience. 2020;42:495-504.

33. Cicin-Sain L, Brien JD, Uhrlaub JL, Drabig A, Marandu TF, Nikolich-Zugich J. Cytomegalovirus infection impairs immune responses and accentuates Tcell Pool changes observed in mice with aging. PLoS Pathog. 2012;8: e1002849.

34. Wertheimer AM, Bennett MS, Park B, Uhrlaub JL, Martinez C, Pulko V, et al. Aging and Cytomegalovirus infection differentially and jointly affect distinct circulating T cell subsets in humans. J Immunol. 2014;192:2143-55.

35. Mekker A, Tchang VS, Haeberli L, Oxenius A, Trkola A, Karrer U. Immune senescence: relative contributions of age and Cytomegalovirus infection. PLoS Pathog. 2012;8:e1002850

36. Redeker A, Remmerswaal EBM, van der Gracht ETI, Welten SPM, Höllt T, Koning $\mathrm{F}$, et al. The contribution of cytomegalovirus infection to immune senescence is set by the infectious dose. Front Immunol. 2018;8.

37. Barton ES, White DW, Cathelyn JS, Brett-McClellan KA, Engle M, Diamond MS, et al. Herpesvirus latency confers symbiotic protection from bacterial infection. Nature. 2007:447:326-9.

38. Furman D, Jojic V, Sharma S, Shen-Orr SS, CJ LA, Onengut-Gumuscu S, et al. Cytomegalovirus infection enhances the immune response to influenza. Sci Transl Med. 2015;7:281 ra43.

39. Smithey MJ, Venturi V, Davenport MP, Buntzman AS, Vincent BG, Frelinger $J A$, et al. Lifelong CMV infection improves immune defense in old mice by broadening the mobilized TCR repertoire against third-party infection. Proc Natl Acad Sci. 2018;115:E6817-25

40. van den Berg SPH, Wong A, Hendriks M, Jacobi RHJ, van Baarle D, Van Beek J. Negative effect of age, but not of latent cytomegalovirus infection on the antibody response to a novel influenza vaccine strain in healthy adults. Front Immunol. 2018;9.

41. Al-Omari A, Aljamaan F, Alhazzani W, Salih S, Arabi Y. Cytomegalovirus infection in immunocompetent critically ill adults: literature review. Ann Intensive Care. 2016;6:110.

42. Bhattacharya S, Andorf S, Gomes L, Dunn P, Schaefer H, Pontius J, et al. ImmPort: disseminating data to the public for the future of immunology. Immunol Res. 2014:58:234-9.

43. Bhattacharya S, Dunn P, Thomas CG, Smith B, Schaefer H, Chen J, et al. ImmPort, toward repurposing of open access immunological assay data for translational and clinical research. Sci Data. 2018;5:180015.

44. Dunn PJ, Thomson E, Campbell J, Smith T, Desborough V, Wiser J, et al. ImmPort: Shared research data for bioinformatics and immunology. 2015 IEEE Int Conf Bioinforma Biomed. IEEE; 2015. p. 607-610.

45. Kaczorowski K, Shekhar K, Nkulikiyimfura D, Dekker CL, Maecker H, Davis MM, et al. Continuous immunotypes describe human immune variation and predict diverse responses. Proc Natl Acad Sci U S A. 2017:114:E6097-106.

46. Benjamini $Y$, Hochberg $Y$. Controlling the false discovery rate: a practical and powerful approach to multiple testing. J R Stat Soc B. 1995;57:289-300.

47. Brizić I, Hiršl L, Britt WJ, Krmpotić A, Jonjić S. Immune responses to congenital cytomegalovirus infection. Microbes Infect. 2018;20:543-51.

48. Hou P-F, Zhu L-J, Chen X-Y, Qiu Z-Q. Age-related changes in CD4+CD25+ FOXP3+ regulatory $T$ cells and their relationship with lung cancer. PLoS One. 2017;12:e0173048.

49. Fessler J, Ficjan A, Duftner C, Dejaco C. The impact of aging on regulatory T-cells. Front Immunol. 2013;4:231.

50. Jagger A, Shimojima Y, Goronzy JJ, Weyand CM. Regulatory T cells and the immune aging process: a mini-review. Gerontology. 2014;60:130-7.

51. Ahmadi KR, Hall MA, Norman P, Vaughan RW, Snieder H, Spector TD, et al. Genetic determinism in the relationship between human CD4+ and CD8+ T lymphocyte populations? Genes Immun. 2001;2:381-7.

52. Fülöp T, Larbi A, Pawelec G. Human T cell aging and the impact of persistent viral infections. Front Immunol. 2013:4:271.

53. Goldeck D, Larsen LA, Christiansen L, Christensen K, Hamprecht K, Pawelec $\mathrm{G}$, et al. Genetic influence on the peripheral blood $\mathrm{cd} 4+\mathrm{t}$-cell differentiation status in CMV infection. Journals Gerontol - Ser A Biol Sci Med Sci. 2016;71: 1537-43.

54. Hassouneh F, Lopez-Sejas N, Campos C, Sanchez-Correa B, Tarazona R, Solana $R$, et al. Differential effect of cytomegalovirus infection with age on the expression of CD57, CD300a, and CD161 on T-cell subpopulations. Front Immunol. 2017;8:649.

55. Northfield J, Lucas M, Jones H, Young NT, Klenerman P. Does memory improve with age? CD85j (ILT-2/LIR-1) expression on CD8+T cells correlates with "memory inflation" in human cytomegalovirus infection. Immunol Cell Biol. 2005;83:182-8.

56. van den Berg SPH, Pardieck IN, Lanfermeijer J, Sauce D, Klenerman P, van Baarle D, et al. The hallmarks of CMV-specific CD8 T-cell differentiation. Med Microbiol Immunol Springer Verlag. 2019;208:365-73.

57. Welten SPM, Redeker A, Franken KL, Benedict CA, Yagita H, Wensveen FM, et al. CD27-CD70 Costimulation controls T cell immunity during acute and persistent Cytomegalovirus infection. J Virol. 2013;87:6851-65.

58. Sierro $S$, Rothkopf R, Klenerman P. Evolution of diverse antiviral CD8+ T cell populations after murine cytomegalovirus infection. Eur J Immunol. 2005;35: $1113-23$.

59. Tu W, Rao S. Mechanisms underlying T cell immunosenescence: aging and cytomegalovirus infection. Front Microbiol. 2016;7:2111.

60. Hurme M. Viruses and immunosenescence - More players in the game. Immun Ageing. BioMed Central Ltd. 2019:16:13.

61. Nikolich-Zugich J, Goodrum F, Knox K, Smithey MJ. Known unknowns: how might the persistent herpesvirome shape immunity and aging? Curr Opin Immunol Elsevier Ltd. 2017;48:23-30.

\section{Publisher's Note}

Springer Nature remains neutral with regard to jurisdictional claims in published maps and institutional affiliations.
Ready to submit your research? Choose BMC and benefit from:

- fast, convenient online submission

- thorough peer review by experienced researchers in your field

- rapid publication on acceptance

- support for research data, including large and complex data types

- gold Open Access which fosters wider collaboration and increased citations

- maximum visibility for your research: over $100 \mathrm{M}$ website views per year

At BMC, research is always in progress.

Learn more biomedcentral.com/submissions 